\title{
Antibacterial and Antifungal Activity of Organic and Peptidic Extracts of Ecuadorian Endophytic Fungi
}

\author{
Eliana Veloz Villavicencio $\mathbb{D}^{\text {, Carolina E. Portero, Alexandra Narvaez-Trujillo* }}$ \\ Plant Biotechnology Research Group, Center for Research on Health in Latin America (CISeAL), Pontificia Universidad Catolica \\ del Ecuador (PUCE), Quito, Ecuador \\ Email: *alexandra.narvaez.t@gmail.com
}

How to cite this paper: Veloz Villavicencio, E., Portero, C.E. and Narvaez-Trujillo, A. (2021) Antibacterial and Antifungal Activity of Organic and Peptidic Extracts of Ecuadorian Endophytic Fungi. Advances in Microbiology, 11, 266-282.

https://doi.org/10.4236/aim.2021.115020

Received: October 27, 2020

Accepted: May 22, 2021

Published: May 25, 2021

\section{Copyright $\odot 2021$ by author(s) and} Scientific Research Publishing Inc. This work is licensed under the Creative Commons Attribution International License (CC BY 4.0).

http://creativecommons.org/licenses/by/4.0/

\begin{abstract}
Antibacterial and antifungal activities of 32 organic and 14 peptidic extracts obtained from twelve endophytic fungi of the Collection of Endophytes Quito-Catolica were tested against the pathogenic bacteria Staphylococcus aureus, Pseudomonas aeruginosa, Serratia marcescens, Escherichia coli and Salmonella enteritidis, and against the fungal oomycete Pythium ultimum. It was observed that the extracts of Marasmiellus candidus (CEQCA-O1113), Xylaria laevis (CEQCA-O1399), Fusarium solani (CEQCA-O1393), Diaporthe helianthi (CEQCA-O1394) and Xylaria sp. (CEQCA-O1400) partially or totally inhibited the microorganisms tested. The extracts CEQCA-O1399.P1 and CEQCA-O1113.D1 showed fungistatic and fungicidal effects against $P$. ultimum, respectively. Six extracts strongly inhibited $S$. aureus, and $E$. coli was strongly inhibited by the extract CEQCA-O1113.E2. Based on a bioassayguided approach, the extracts with strong bioactivity in the antibacterial assays by an agar diffusion method were also tested by a disk diffusion method, and the minimal inhibitory concentrations were determined by a microdilution assay. The most bioactive extract, CEQCA-O1113.D1, was also purified by high performance liquid chromatography. The extract recovered its initial bioactivity against $S$. aureus in two fractions after the purification. Overall, the results of this study highlight the potential of the fungal endophytes as producers of bioactive compounds.
\end{abstract}

\section{Keywords}

Bioactive Compounds, Fungal Endophytes, Growth Inhibition Assays, Pathogenic Bacteria 


\section{Introduction}

The ability of the microorganisms to synthesize a variety of compounds has attracted the attention of researchers to bioprospecting for natural products in bacteria, fungi and actinomycetes [1]. Current challenges such as emerging antibiotic-resistant bacteria, environmental degradation, severe fungal infections and the lack of treatment for diseases such as neglected tropical diseases and cancer could be overcome by compounds produced by microorganisms [2] [3] [4].

Endophytic fungi live within plant tissues asymptomatically and are synthesizers of chemical compounds that provide protection to the plant host against herbivores and pathogens [1] [2] [3] [5] [6]. The diversity of the endophytic fungi and the variety of compounds they can produce (alkaloids, terpenoids, aldehydes, esters, alcohols, etc.), are in close association with their ability to inhibit other organisms [7] [8]. Thus, fungal endophytes comprise an interesting source of compounds useful for diverse applications in medicine, agriculture and industry.

Ecuador's geography, which ranges from seacoast to arid mountains and to Amazonian jungle, provides a diversity of ecosystems that contain a uniquely high and underexplored biological diversity [9]. The dynamics of the ecological interactions among different taxonomic groups present at each ecosystem may enhance the production of natural products with high potential for bioactivity. Moreover, exploration of unique habitats has been shown to be an effective strategy [2]. The Amazonian forest in particular is touted as potentially the largest drug dispensary in the world [7] [10]. This potential of the Ecuadorian plants to host interesting fungal endophytes with diverse biotechnological applications inspired the creation of the Collection of Endophytes Quito-Catolica, CEQCA by its acronym. Currently, the Collection counts with around 4000 endophytic fungi isolated from plants collected in tropical rainforests, lowlands, and Andean ecosystems.

The aim of our study is to evaluate the antibacterial and antifungal activities of extracts obtained from a selection of twelve endophytic fungi stored at the CEQCA. This study constitutes an important basis for the knowledge of the potential of Ecuadorian endophytes for bioprospection of natural products, and also gives an added value to Ecuadorian plant biodiversity, promoting the conservation of both ecosystems and plants as hosts of novel endophytes with promising biotechnological applications.

\section{Materials and Methods}

\subsection{Fungal Cultures}

The fungi stored at the CEQCA were previously identified by comparing the consensus sequences of the internal transcribed spacer (ITS) regions 1 and 4 with the sequences available at the NCBI GenBank using the Basic Local Alignment Search Tool (BLAST). Twelve endophytic fungi of the CEQCA were selected for this study based mainly on two criteria: 1) potential as new species (identity percent $<95 \%$ with other sequences in BLAST or identification not resolved at least until genus after comparing the sequences in BLAST) and 2) bio- 
activity of the fungal isolates reported in previous assays (Table 1). Two isolates (CEQCA-M1179 and CEQCA-M1214) did not meet the criteria but were included since they were not tested for bioactivity before. The fungi were cultivated on Potato Dextrose Agar (PDA) (Difco, USA) plates at $21^{\circ} \mathrm{C}$ for seven days, and then upscaled to $1 \mathrm{~L}$ of Potato Dextrose Broth (PDB) (Difco, USA) until abundant mycelia was observed in culture.

\subsection{Organic Extraction of Secondary Metabolites}

The extraction of secondary metabolites with organic solvents was performed as suggested by Bascom-Slack et al. [11] with modifications. The mycelia were filtered through cheesecloth and then through Whatman $\mathrm{N}^{\circ} 1$ filter paper, and discarded. The broth was extracted twice with $300 \mathrm{~mL}$ of dichloromethane (DCM). The filtrate was collected and reserved. After the DCM extraction, the broth was extracted with ethyl acetate (EA) following the same procedure. Each fraction (DCM and EA) was concentrated separately either with an evaporator Büchi Rotavapor RII (Fischer Scientific, USA) or a GeneVac concentrator (Fisher Scientific, USA) in $2 \mathrm{~mL}$ glass vials. The extracts were resuspended in methanol and labelled accordingly with the letters $\mathrm{D}$ for DCM or E for EA and stored at $+4^{\circ} \mathrm{C}$.

Table 1. Endophytic fungi selected for this study. Information of their plant hosts is included.

\begin{tabular}{|c|c|c|c|c|c|c|c|}
\hline \multirow{2}{*}{ Fungal species } & \multirow{2}{*}{ Fungus ID } & \multirow{2}{*}{$\begin{array}{c}\text { Province of } \\
\text { collection/ecosystem }\end{array}$} & \multirow{2}{*}{$\begin{array}{c}\text { Reference } \\
\text { GenBank } \\
\text { accession } \\
\text { number }\end{array}$} & \multirow{2}{*}{$\begin{array}{c}\text { Identity } \\
\text { percent } \\
\text { in BLASTn }\end{array}$} & \multirow{2}{*}{$\begin{array}{c}\text { Bioactive in } \\
\text { previous } \\
\text { assays }\end{array}$} & \multicolumn{2}{|c|}{ Plant host } \\
\hline & & & & & & Family & Species \\
\hline Periconia sp. & CEQCA-M1179 & Manabi/ Coastal dry forest & KC771468 & $100 \%$ & No tested & Violaceae & Unknown \\
\hline $\begin{array}{c}\text { Virgaria } \\
\text { boninensis }\end{array}$ & CEQCA-M1193 & Manabi/ Coastal dry forest & KC771473 & $91 \%$ & Yes & Arecaceae & Unknown \\
\hline $\begin{array}{c}\text { Entonaema } \\
\text { pallida }\end{array}$ & CEQCA-M1214 & Manabi/ Coastal dry forest & KC771479 & $100 \%$ & No tested & Rubiaceae & Simira sp. \\
\hline Xylaria sp. & CEQCA-M1240 & Manabi/ Coastal dry forest & KC771483 & $100 \%$ & Yes & Mimosaceae & Unknown \\
\hline Pleosporales sp. 1 & CEQCA-O1055 & Orellana/ Amazon rainforest & KC771506 & $100 \%$ & No & Piperaceae & Pipersp. \\
\hline Pleosporales sp. 2 & CEQCA-O1090 & Orellana/ Amazon rainforest & KC771509 & $100 \%$ & No & Meliaceae & $\begin{array}{c}\text { Guarea } \\
\text { kunthiana }\end{array}$ \\
\hline Ascomycota sp. & CEQCA-O1111 & Orellana/ Amazon rainforest & KC771513 & $100 \%$ & Yes & Violaceae & $\begin{array}{c}\text { Corynostylis } \\
\text { arborea }\end{array}$ \\
\hline $\begin{array}{c}\text { Marasmiellus } \\
\text { candidus }\end{array}$ & CEQCA-O1113 & Orellana/ Amazon rainforest & MN173348 & $100 \%$ & Yes & Combretaceae & Unknown \\
\hline Fusarium solani & CEQCA-O1393 & Orellana/ Amazon rainforest & JX476948 & $100 \%$ & Yes & Malvaceae & Herrania mariae \\
\hline $\begin{array}{l}\text { Diaporthe } \\
\text { helianthi }\end{array}$ & CEQCA-O1394 & Orellana/ Amazon rainforest & AY746005 & $100 \%$ & Yes & Malvaceae & Herrania mariae \\
\hline Xylaria laevis & CEQCA-O1399 & Orellana/ Amazon rainforest & JX476949 & $100 \%$ & Yes & Malvaceae & $\begin{array}{c}\text { Theobroma } \\
\text { cacao }\end{array}$ \\
\hline Xylariaceae sp. & CEQCA-O1400 & Orellana/ Amazon rainforest & JX476952 & $100 \%$ & Yes & Malvaceae & $\begin{array}{c}\text { Theobroma } \\
\text { cacao }\end{array}$ \\
\hline
\end{tabular}




\subsection{Extraction of Peptides}

The protocol followed by Panizel et al. [12] was modified for the peptide extraction. The fungal liquid cultures were filtered, and the mycelia discarded. The broth was placed together with $50 \mathrm{~g}$ of Amberlite XAD-7HP beads (Acros Organics, USA) and was agitated overnight, after which the aqueous phase was discarded, and the beads were placed into a clean tray and washed three times with MilliQ water. The wet beads were placed over filter paper until they dried completely and then covered with methanol. After five minutes, the beads were mixed for ten minutes with a magnetic stirrer and the methanol was collected. At this point, the methanol presented a yellowish color. The beads washed until the methanol collected was completely transparent. All the methanol was concentrated with a Büchi Rotavapor RII evaporator (Fischer Scientific, USA). The extracts were resuspended in methanol and distilled water. A total of 14 peptidic extracts were obtained and labelled accordingly with the letter $\mathrm{P}$ to differentiate from EA and DCM extracts. The extracts were stored at $+4^{\circ} \mathrm{C}$.

\subsection{Thin Layer Chromatography (TLC) of Peptidic Extracts}

Before testing the peptidic extracts against the selected microorganisms, a TLC was run to confirm the presence of peptides in the samples and to validate the extraction protocol previously performed. The mobile phase consisted in ethyl acetate, methanol, and distilled water in proportion 120:60:20. Baker-flex Silica Gel IB2-F plates $(20 \times 20 \mathrm{~cm})$ (Fischer Scientific, USA) were used as stationary phase. The plate was heated for three minutes and the samples were loaded $1 \mathrm{~cm}$ above a reference line. The samples were let dry for approximately one minute before the run was performed. The samples ran until they reached two thirds of the plate. The plate was let dry and then sprayed with ninhydrin monohydrate (Sigma, USA) previously prepared in methanol (33.3 g in $1 \mathrm{~L}$ ). After 15 minutes, purple spots were observed on the plate, confirming the presence of peptides in the samples [13].

\subsection{Microorganisms Assayed}

Assays were performed with human pathogenic bacteria Staphylococcus aureus (ATCC 25923), Pseudomonas aeruginosa (ATCC 27853), Serratia marcescens (ATCC 13880), Escherichia coli (ATCC 25922) and Salmonella enteritidis (ATCC 13076) as well as the fungal oomycete Pythium ultimum stored at the CEQCA.

\subsection{Bioassays against $P$, ultimum}

The bioassays against $P$. ultimum were performed as indicated by Bascom-Slack et al. [11] with modifications. P. ultimum was grown on PDA plates for three days at room temperature. Each plate was inoculated with two extracts, a negative control (methanol only) and a positive control (fungus only). A total of 10 $\mu \mathrm{L}$ of each extract were placed on the plates, applying $5 \mu \mathrm{L}$ first, letting the extract dry and then applying the last $5 \mu \mathrm{L}$. Agar plugs $(3 \times 3 \mathrm{~mm})$ of the three- 
day-old $P$. ultimum cultures were cut and placed with the side of the mycelium directly touching the spot where the extracts were previously applied, and over the positive control spot. The plates were kept at room temperature for three days. The diameter of growth of $P$. ultimum in each plate was recorded daily. On the fourth day, those plugs that did not show any fungal growth were transferred to fresh PDA plates to verify if the extracts had a fungistatic or fungicidal effect over the fungus. The average of the growth diameter was expressed as growth percentage compared to the methanol control.

\subsection{Antibacterial Assays}

\subsubsection{Agar Diffusion Method}

The antibacterial activity of organic and peptidic extracts where first tested with an agar diffusion method modified from Bascom-Slack et al. [11]. Plates containing Luria-Bertani (LB) agar (Difco, USA) were marked and divided into four quadrants. Each plate was inoculated with two extracts, one methanol control and one bacterial growth control (no methanol or extract applied). The selected bacteria where grown on LB agar for 24 hours at $37^{\circ} \mathrm{C}$. A bacterial suspension was prepared in a $0.8 \%(\mathrm{w} / \mathrm{v}) \mathrm{NaCl}$ solution, and the turbidity was adjusted to $0.5 \mathrm{MacFarland}$ scale prior to the inoculation of the plates [14]. After that, $10 \mu \mathrm{L}$ of the extracts were pipetted on the plates. The extracts were let dry and the adjusted bacterial suspensions were inoculated with cotton swabs. The plates were incubated at $37^{\circ} \mathrm{C}$ for 18 hours. The antibacterial activity was detected by the formation of an inhibition zone on the spots were the extracts were applied. The antibacterial activity of the extracts was catalogued as total inhibition, partial inhibition or no inhibition, according to the growth of the bacteria observed on the plates.

\subsubsection{Disk Diffusion Method}

Only the extracts that showed total inhibition using the agar diffusion method were tested by the disk diffusion method. The disk diffusion method followed the recommendations given by the Clinical and Laboratory Standards Institute [15]. The bacteria were grown on Mueller-Hinton agar (MHA) (Difco, USA) for 18 hours at $37^{\circ} \mathrm{C}$. A bacterial suspension was prepared as described in section 2.7.1. [14]. Whatman diffusion disks of $6 \mathrm{~mm}$ of diameter (Sigma Aldrich, USA) were loaded with the extracts of interest. Each MHA plate contained two disks loaded with the extracts of interest, one disk loaded with methanol only and one empty disk (no methanol or extract loaded). The adjusted bacterial suspensions were inoculated evenly with cotton swabs and the disks onto the agar. The plates kept at $37^{\circ} \mathrm{C}$ for 18 hours. The diameter of the inhibition zones was measured and recorded as the average of three replicates with their standard deviation.

\subsection{Determination of the Minimal Inhibitory Concentration (MIC)}

The MIC was only determined for those extracts that presented a total inhibition of the microorganisms tested in both agar diffusion and disk diffusion methods. 
Briefly, the bacteria were grown on Mueller-Hinton agar (MHA) (Difco, USA) for 18 hours at $37^{\circ} \mathrm{C}$. A bacterial suspension was prepared as described in section 2.7.1 [14]. Eight two-fold dilutions of the extracts were prepared and added to polystyrene 96-well plates (Corning, USA) with $90 \mu \mathrm{L}$ of Mueller-Hinton broth (MHB) (Difco, USA), $10 \mu \mathrm{L}$ of the inoculum and $10 \mu \mathrm{L}$ of each dilution [14] [16]. Additionally, three controls were prepared: $90 \mu \mathrm{L}$ of $\mathrm{MHB}$ plus $10 \mu \mathrm{L}$ methanol, $90 \mu \mathrm{L}$ of MHB plus $10 \mu \mathrm{L}$ of inoculum, and $90 \mu \mathrm{L}$ of MHB plus 10 of $\mu \mathrm{L}$ inoculum and $10 \mu \mathrm{L}$ of the antibiotic Gibco Penicillin Streptomycin (10,000 $\mathrm{U} / \mathrm{mL}$ ) (Thermo Fischer Scientific, USA). The plates were incubated at $37^{\circ} \mathrm{C}$ for 18 hours and read with an iMark microplate reader (BioRad, USA) at $630 \mathrm{~nm}$.

\subsection{Purification of Bioactive Extracts}

The extracts that showed partial and total inhibition in both agar diffusion and disk diffusion methods were purified by high performance liquid chromatography (HPLC), following the method suggested by Forcina et al. [17] with modifications. The analyses were performed in an HPLC system (Gilson, USA) located in the West Campus at Yale University, New Haven (USA). The extracts were filtered with $2 \mathrm{~mL}$ Millipore Ultrafree column filters (Merck Millipore, USA) by centrifugation at $3000 \mathrm{rpm}$, and at room temperature $\left(21^{\circ} \mathrm{C}\right)$ for one minute. A second centrifugation was performed by adding methanol to recover as much of extract as possible from the column filters. The filtered extract was transferred to a sterile glass vial and injected to the HPLC equipment. The HPLC run was performed using a Waters SunFire C18 column $(5 \mu \mathrm{M} ; 20 \times 250 \mathrm{~mm}$ ) (Waters, USA). The elution was carried out using a gradient of $0 \%-100 \%$ acetonitrile at a rate of $10 \mathrm{~mL} / \mathrm{min}$ for 40 minutes, at $254 \mathrm{~nm}$ and $215 \mathrm{~nm}$. The results were analysed with the software Trilution LC (Gilson, USA). The fractions that showed sharp peaks were collected and lyophilized overnight in a GeneVac concentrator (Fisher Scientific, USA). The bioactivity of the fractions was verified by a microdilution assay performed in polystyrene 96 -well plates (Corning, USA). Briefly, $90 \mu \mathrm{L}$ of media was added to each well, followed by $10 \mu \mathrm{L}$ of bacterial inoculum previously adjusted to $0.5 \mathrm{MacFarland}$ scale and $10 \mu \mathrm{L}$ of the corresponding HPLC fraction. Each fraction was tested in triplicate. The plate was read by a microplate reader integrated with the Gen5 Microplate Reader and Imager software (BioTek, USA). The reading was performed every ten minutes for 12 hours at $600 \mathrm{~nm}$, under continuous agitation at medium speed and under constant temperature $\left(35^{\circ} \mathrm{C}\right)$. The results were observed as bacterial growth curves generated by the software GraphPadPrism (GraphPad Software, USA).

\subsection{Mass Spectrometry (MS) Analysis}

The HPLC fractions that preserved their bioactivity after fractionation were sent to MS analysis to the Molecular Innovations Center in the West Campus at Yale University. The results were analyzed with the software MassHunter Workstation (Agilent Technologies, USA). 


\subsection{Statistical Analyses}

The data obtained from the antifungal and antibacterial assays were analyzed by a one-way analysis of variance (ANOVA) and a Tukey test to determine statistical significance. A $p$-value of $<0.05$ was considered as statistically significant. The experiments were carried out with a completely randomized design with three replicates. The analyses were performed with the IBM SPSS Statistics software (IBM, USA).

\section{Results}

A total of 46 extracts were tested and 42 of them showed bioactivity against at least one of the microorganisms tested. All the ninhydrin monohydrate tests were positive, which confirmed the presence of peptides within the samples.

\subsection{Antifungal Assays against P. ultimum}

The extract of Marasmiellus candidus CEQCA-O1113.D1, and the peptidic extract of Xylaria laevis CEQCA-O1399.P1, significantly inhibited the growth of $P$. ultimum after the three days of the experiment ( $0 \%$ of growth, $p<0.05$ ). The fungal agar plugs that were exposed to the extract CEQCA-O1399.P1 showed mycelial growth after being transferred to a fresh PDA plate (fungistatic effect), whereas the fungal agar plugs that were exposed to the extract CEQCA-O1113.D1 showed no mycelial growth on a fresh PDA plate (fungicidal effect).

\subsection{Antibacterial Assays}

By using the agar diffusion method, we observed that $S$. aureus was totally inhibited by six extracts, while only one extract totally inhibited $E$. coli. None of the extracts showed total inhibition against the other bacteria but 29 extracts partially inhibited at least one of the bacteria tested, as shown in Table 2.

Regarding the peptidic extracts, a partial inhibition of $S$. aureus was mostly observed in those extracts obtained from Xylaria sp. (CEQCA-M1240.P1), Pleosporales sp. 1 (CEQCA-O1055.P1), Diaporthe helianthi (CEQCA-O1394.P1 and P2), and Ascomycota sp. (CEQCA-O1111.D1). The latter extract partially inhibited $S$. enteritidis as well. The peptidic extract of Xylariaceae sp. (CEQCAO1400.P2) was the only one that totally inhibited $S$. aureus.

The extracts that totally inhibited $S$. aureus and $E$. coli were tested by the disk diffusion method. The extract CEQCA-O1113.D1 presented the biggest inhibition zone (17.67 $\mathrm{mm} \pm 1.2)$ against $S$. aureus (Figure 1, Table 3).

\subsection{MIC Determination}

Table 3 shows the MIC values obtained after performing a microdilution test of the crude extracts that showed total inhibition against $E$. coli and $S$. aureus. The MIC values ranged from 4.4 to $237.42 \mathrm{mg} / \mathrm{mL}$. The lowest MIC observed was of the extract CEQCA-O1113.D1 against $S$. aureus. The MIC of the extract CEQCA-O1113.E1 was not detected, suggesting that the MIC is found within a 
non-assayed concentration between $15.83 \mathrm{mg} / \mathrm{mL}$ (concentration of crude extract) and $7.93 \mathrm{mg} / \mathrm{mL}$ (first dilution).

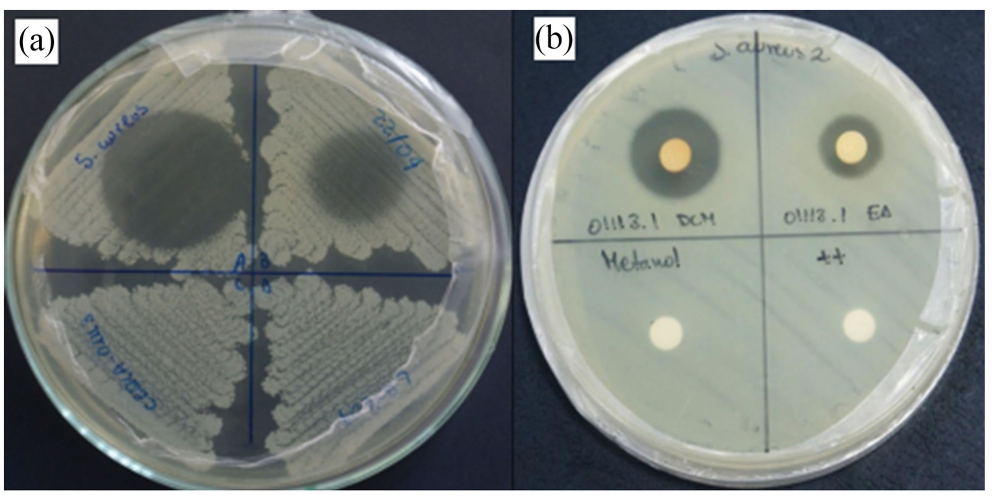

Figure 1. Comparison of the bioassays performed using the agar diffusion and the disk diffusion methods against $S$. aureus. The upper quadrants of both plates correspond to the extracts CEQCA-O1113. D1 (left) and CEQCA-O1113.E1 (right), whereas the quadrants below correspond to the methanol control (down left) and bacterial control (down right). (a) Agar diffusion method; (b) Disk diffusion method.

Table 2. Bioactivity of 46 fungal extracts evaluated by the agar diffusion method.

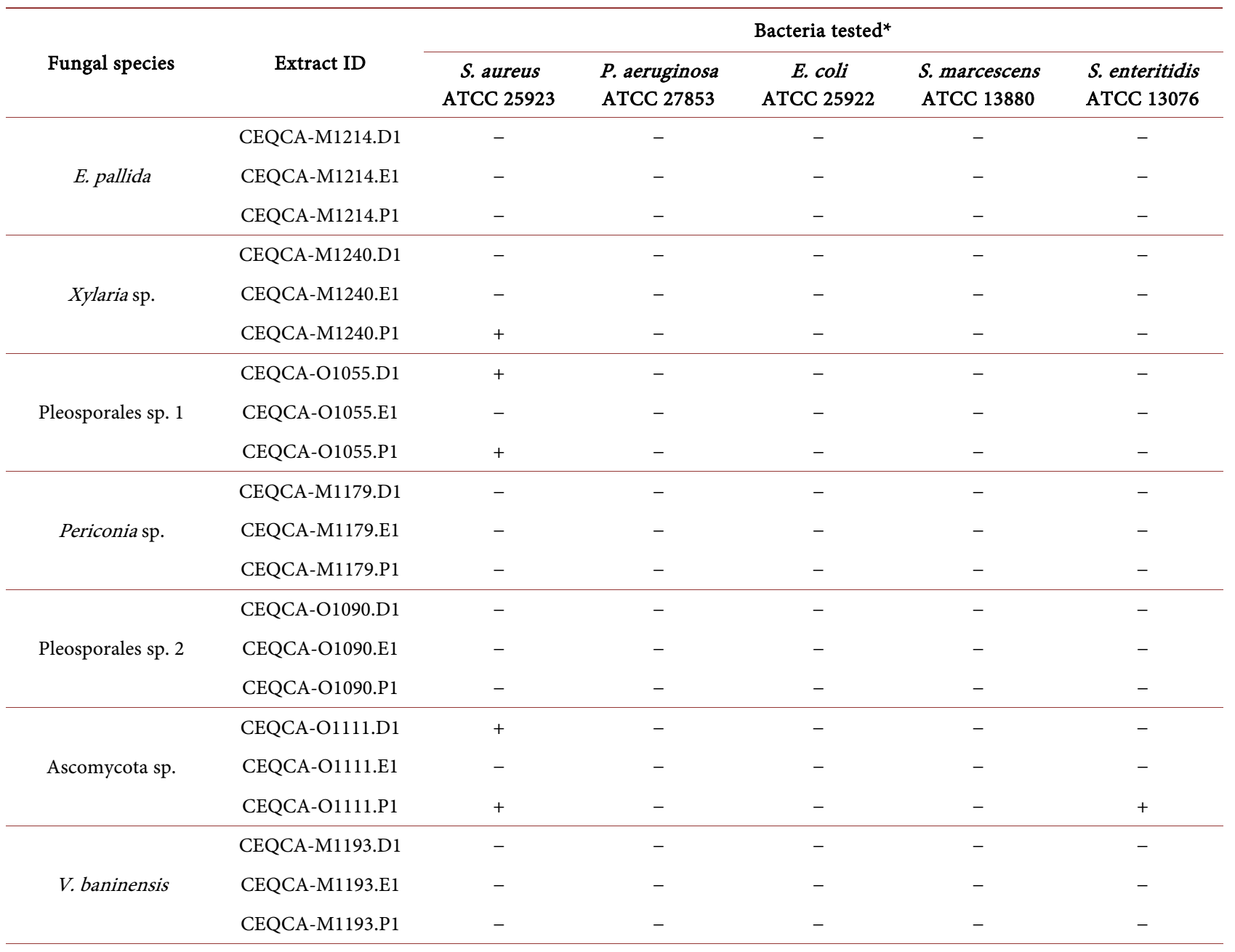




\section{Continued}

\begin{tabular}{|c|c|c|c|c|c|c|}
\hline & CEQCA-O1113.D1 & ++ & - & - & - & - \\
\hline & CEQCA-O1113.D2 & + & - & + & - & - \\
\hline \multirow[t]{5}{*}{ M. candidus } & CEQCA-O1113.E1 & ++ & - & - & - & - \\
\hline & CEQCA-O1113.E2 & + & - & ++ & + & - \\
\hline & CEQCA-O1113.P1 & - & - & - & - & - \\
\hline & CEQCA-O1393.D1 & - & - & - & - & - \\
\hline & CEQCA-O1393.D2 & - & - & - & - & - \\
\hline \multirow[t]{5}{*}{ F. solani } & CEQCA-O1393.E1 & - & + & - & + & + \\
\hline & CEQCA-O1393.E2 & ++ & + & + & + & + \\
\hline & CEQCA-O1393.P1 & - & - & - & - & - \\
\hline & CEQCA-O1400.D1 & - & - & - & - & - \\
\hline & CEQCA-O1400.E1 & - & - & - & - & - \\
\hline \multirow{4}{*}{ Xylariaceae sp. } & CEQCA-O1400.P1 & + & - & - & - & - \\
\hline & CEQCA-O1400.P2 & ++ & - & - & - & - \\
\hline & CEQCA-O1394.D1 & - & - & - & - & - \\
\hline & CEQCA-O1394.D2 & - & - & - & - & - \\
\hline \multirow{6}{*}{ D. helianthi } & CEQCA-O1394.E1 & + & - & - & - & - \\
\hline & CEQCA-O1394.E2 & ++ & + & + & + & - \\
\hline & CEQCA-O1394.P1 & + & - & - & - & - \\
\hline & CEQCA-O1394.P2 & + & - & - & - & - \\
\hline & CEQCA-O1399.D1 & + & - & - & - & - \\
\hline & CEQCA-O1399.D2 & + & - & - & + & + \\
\hline \multirow[t]{3}{*}{$X$. laevis } & CEQCA-O1399.E1 & + & + & - & + & + \\
\hline & CEQCA-O1399.E2 & ++ & + & + & + & + \\
\hline & CEQCA-O1399.P1 & - & - & - & - & - \\
\hline
\end{tabular}

${ }^{*}$ Symbols indicate - , no inhibition; +, partial inhibition; ++, full inhibition.

Table 3. Minimal inhibitory concentrations (MICs) of the extracts that showed strong bioactivity by the disk diffusion method.

\begin{tabular}{|c|c|c|c|c|}
\hline Extract ID & Bacterium tested & $\begin{array}{l}\text { Initial concentration of } \\
\text { the extract }(\mathrm{mg} / \mathrm{mL})\end{array}$ & $\begin{array}{l}\text { Average diameter of } \\
\text { the inhibition zone }(\mathrm{mm})^{*}\end{array}$ & $\mathrm{MIC}(\mathrm{mg} / \mathrm{mL})$ \\
\hline CEQCA-O1113.D1 & S. aureus ATCC 25923 & 35.13 & $17.67 \pm 1.2^{\mathrm{a}}$ & 4.4 \\
\hline CEQCA-O1113.E1 & S. aureus ATCC 25923 & 15.85 & $12.33 \pm 0.6^{\mathrm{a}}$ & Between 7.93 and 15.85 \\
\hline CEQCA-O1399.E2 & S. aureus ATCC 25923 & 102.6 & $8 \pm 1^{\mathrm{a}}$ & 25.65 \\
\hline CEQCA-O1393.E2 & S. aureus ATCC 25923 & 383.2 & $8.67 \pm 0.6$ & 47.9 \\
\hline CEQCA-O1394.E2 & S. aureus ATCC 25923 & 105.8 & $8.33 \pm 0.6$ & 26.45 \\
\hline CEQCA-O1400.P2 & S. aureus ATCC 25923 & 949.67 & $9 \pm 0$ & 237.42 \\
\hline CEQCA-O1113.E2 & E. coli ATCC 25922 & 91.2 & $10.33 \pm 1.6$ & 45.6 \\
\hline
\end{tabular}

*The same superscript letter "a" indicates a significant difference $(p<0.05)$ between the diameters of the inhibition zones. 


\subsection{Purification of Extracts by HPLC}

The organic extract CEQCA-O1113.D1, that presented the strongest bioactivity in the antimicrobial assays, was fractioned by HPLC. Only two fractions of the extract (fraction 45 and 46) preserved the bioactivity of the crude extract against $S$. aureus after the purification. A bacterial growth curve (absorbance vs time) was built based on the results of the microdilution test (Figure 2). The fraction 45 fully inhibited $S$. aureus growth, as observed in Figure 2(a). The fraction 46 showed inhibition as well (Figure 2(b)), but not as strong as the bioactivity observed with fraction 45 . The MS results showed that fraction 45 required additional purification, since there were too many possible compounds present in the sample and the chromatogram was not fully resolved.

\section{Discussion}

Fungal endophytes are well-known producers of a variety of secondary metabolites with a wide range of bioactivities against bacteria, fungi, and other microbes [2]. It has been hypothesized that the endophytes produce those compounds in nature to inhibit the growth of their competitors [5]. Remarkably, when produced in vitro, these compounds maintain bioactivity and can be potentially used in medicine, industry, and agriculture.

In the present study, a screening of 46 extracts obtained from 12 endophytic fungi selected from the CEQCA was performed to test their inhibitory capacities against the ATCC bacteria $S$. aureus, E. coli, $S$. marcescens, $P$. aeruginosa and $S$. enteritidis, and against the plant pathogenic oomycete $P$. ultimum. We found

(a) Fraction 45 (CEQCA-O1113 DCM.1)

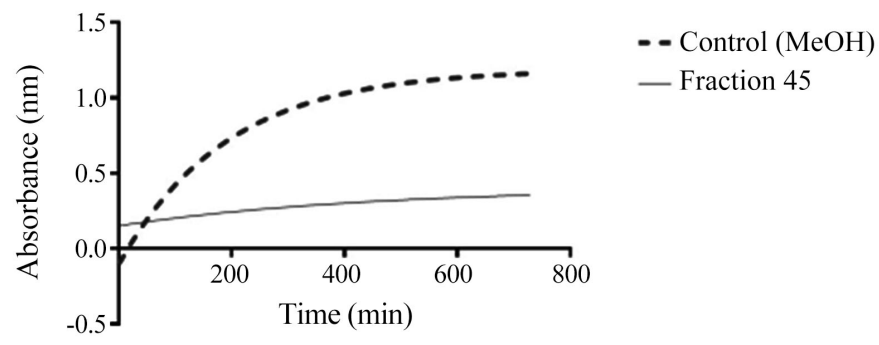

(b) Fraction 46 (CEQCA-O1113 DCM.1)

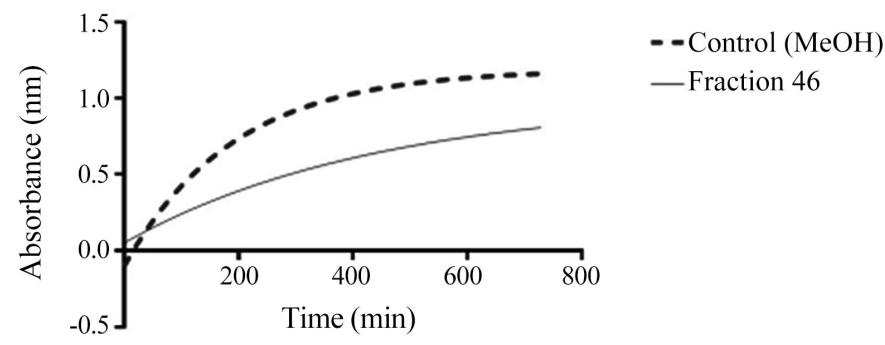

Figure 2. Curves of bacterial growth of $S$. aureus against the fractions 45 and 46 of the extract CEQCA-O1113.D1. Dotted line: fraction tested. Solid line: methanol control. (a) Fraction 45. (b) Fraction 46. 
that 42 out of the 46 extracts tested showed partial or total inhibition against at least one of the microorganisms tested, therefore demonstrating the potential utility of plant fungal endophytes for mining biomolecules that may be developed into new therapeutic agents.

The culture conditions were especially important to harvest the secondary metabolites when culturing the fungus Marasmiellus candidus (CEQCA-O1113). The bioactivity of this fungus against $S$. aureus and $P$. ultimum was apparently conditioned by the guttation of dark brown droplets produced by the mycelia. These exudates were not abundant in the second round of organic extraction, and this might be why the extracts CEQCA-O1113.D2 and E2 did not showed the strong bioactivity observed in the extracts from the first round of extraction (D1 and E1). Guttation is the active secretion of water and dissolved materials, and is a common phenomenon observed in plants and fungi [18]. The composition of the droplets has not been studied in detail. However, it has been reported that fungal guttation droplets are important reservoirs of enzymes, mycotoxins and secondary metabolites such as penicillin, as reported in the droplets of Penicillium sp. [18] [19] [20]. Therefore, it has been hypothesized that guttation droplets take part in important physiological processes such as the maintenance of the mycelial growth rate under poor water availability and defense against other microorganisms [21]. Nevertheless, it is important to note that the formation of fungal guttation droplets occur at random conditions in vitro, which makes it difficult to study their composition and determine the conditions to enhance their production in vitro. According to Schmidt and Spiteller [20], there is no biological trigger for their production identified so far, which may explain why we did not find the droplets in all the plates of $M$. candidus.

The production of antioxidants, sesquiterpenoids and a mellein derivative with potential to inhibit acethylcholinesterase, which can potentially treat Alzheimer disease, have been reported in Marasmiellus species [22] [23] [24]. The production of terpenes such as 1,8-cineole has been also studied in other genera within the Basidiomycota and in the ascomycetous family Xylariaceae, suggesting the potential of endophytic fungi to produce insect-repellent and insecticidal compounds, as well as adjuvants for the attenuation of the inflammatory responses in viral infections such as the H1N1 influenza in mice [25], among other uses (flavoring and fragrance production) [26] [27]. In our study, we observed that the spectrum of activity of the extracts of $M$. candidus was broad, with strong bioactivity against $S$. aureus, $E$. coli and $P$. ultimum. It would be interesting to find out if the extracts of $M$. candidus can inhibit other microorganisms and have other bioactivities, such as anticancer activity, since in a study performed by Strobel et al. [28], one fungal extract that previously showed bioactivity against $P$. ultimum, showed cytotoxic activity against breast cancer cell lines BT-20 as well.

The extracts of Xylaria laevis (CEQCA-O1399), Fusarium solani (CEQCAO1393), D. helianthi (CEQCA-O1394) and Xylaria sp. (CEQCA-O1400) either partially or totally inhibiting the bacteria tested and $P$. ultimum. A wide range of 
bioactivities has been reported in fungi of these genera. A wide variety of bioactivities have been found in Xylaria species, including antibacterial activity of peptides, terpenes, diterpenes, among others against methicillin-resistant $S$. aureus, E. coli, Shigella sp., Mycobacterium tuberculosis, Listeria monocytogenes and other human pathogenic bacteria [29]. Other biological activities of Xylaria include anticancer activity against the cell lines KB, MCF-7 and NCI-H187, antimalarial activity against Plasmodium falciparum $\mathrm{K} 1$, antifungal activity against Candida albicans [30] [31], as well as anti-inflammatory activity [32]. Xyolide, a compound isolated from Xylaria feejeensis, showed a strong inhibitory capacity against the fungus $P$. ultimum [33]. Thus, we confirmed that the genus $X y l a r i a$ is a good source for mining of secondary metabolites with potential in drug discovery.

Fungi of the genus Diaporthe are also good producers of bioactive secondary metabolites. Their genomes encode for enzymes such as sesquiterpenes synthases with a wide variety of bioactivities [27]. In the present study, we found strong bioactivity against $S$. aureus and partial activity against the other bacteria tested with the extracts of $D$. helianthi. Antibacterial activities have been previously reported in fungi of the genus Diaporthe. Diaporone A, a compound isolated from an EA extract of Diaporthe sp. showed moderate antibacterial activity against the soil bacterium Bacillus subtilis and also moderate anticancer activity [34]. A potent triterpenoid active against $S$. aureus, $P$. aeruginosa, Streptococcus pyogenes, E. coli, and B. subtilis has been also isolated from Diaporthe species, as well as variety of polyketides, peptides, and terpenoids [35] [36].

The EA extracts we obtained from Fusarium solani (CEQCA-O1393) were bioactive against all the bacteria tested. The wide array of metabolites secreted by fungi of the genus Fusarium is due to a great genetic variability within the genus, which affects its biology and ecology [37] [38]. A diversity of quinones with antimicrobial activities against $S$. aureus, E. coli, P. aeruginosa, Aspergillus flavus and $A$. niger have been previously observed [39]. Focusing on F. solani, wellknown drugs have been isolated from this species, including quinine, camptothecin and taxol [37]. Altogether, these findings show the potential of Fusarium species as synthesizers of chemically diverse compounds that can be exploited in drug discovery.

The peptidic extracts obtained in this study showed moderate inhibitory activities against the bacteria tested, and it was notable the fungistatic activity of the extract CEQCA-O1400.P2 from Xylaria sp. against P. ultimum. Antimicrobial peptides are small molecules highly appreciated in drug discovery due to their low toxicity, easy diffusion through membranes and low chance of the microorganisms to develop resistance against the peptide [40]. The antimicrobial peptides also possess different mechanisms of action against the microorganisms, including perforation of cell membranes, inhibition of protein synthesis, inhibition of cell wall synthesis and direct DNA damage [41] [42]. These characteristics supported our idea of extracting and testing the bioactivity of the peptidic extracts from our fungal isolates. Excluding the bioactivity of the extract 
CEQCA-O1400.P2 against $P$. ultimum, only partial inhibitions were observed against the other pathogens tested. However, the protocol for peptide extraction worked well, allowing future extractions from other fungal isolates of the CEQCA.

Other studies support the potential of the peptides produced by endophytic fungi as therapeutic agents and for industrial applications. Ibrahim et al. (2020) found new cyclic pentapeptides from the fungus Xylaria ellisii with strong bioactivities against Gram negative bacteria [43]. Besides, cyclic peptides produced by fungi of the genus Epichloë might help the plant to be resistant against herbivores [44], feature that could be useful in the development of pesticides. Other cyclic peptides isolated from Fusarium species and Aspergillus tamarii showed inhibitory activities against plant pathogens such as $P$. ultimum and Rhizoctonia solani, and also cytotoxic activity, respectively [45].

It is interesting to notice that the fungi F. solani, Xylaria laevis and Xylariaceae sp. that showed a wide range of bioactivities, were isolated from the plants Herrania mariae and Theobroma cacao. According to the Encyclopedia of Useful Plants of Ecuador (2008), these plant species have ethnobotanical uses in the Ecuadorian Amazon. The leaves are used to treat snake bites, as well as tumours and ulcers [46]. The endophytic fungi might have a role in the medicinal properties observed in $H$. mariae and $T$. cacao, since the endophytes influences the production of metabolites in the host and vice versa [47] [48]. Future studies should be performed to see the interaction of fungi and host plants in the production of bioactive secondary metabolites.

\section{Conclusions}

Our results indicate that the endophytic fungi of the CEQCA isolated from Ecuadorian plants have potential to produce antibacterial and antifungal compounds. Ecuadorian endophytic diversity is higher compared to temperate sites and other tropical locations, as observed in Panama by Arnold and Lutzoni [49]. Therefore, we may expect that the diversity of chemically interesting compounds is also high, and may show a wide range of bioactivities as observed in Ecuadorian endophytic fungi of the family Xylariaceae [7] [26] [33].

Further studies are needed to purify and identify the molecules responsible of the bioactivities observed. Additionally, efforts should be put in the identification of those fungi that were bioactive but lack taxonomic identification. The knowledge of their identity would shed light on the metabolites that they can potentially produce.

\section{Acknowledgements}

The authors thank Professor Scott Strobel from Yale University, who allowed E.V.V. to perform HPLC and MS analysis as part of the summer component of the course "Rainforest Expedition \& Laboratory". The authors also acknowledge the Ministry of Environment of Ecuador for providing the Framework Contract for Access to Genetic Resources, which allowed the experimentation with the 
fungal isolates. The Pontifical Catholic University of Ecuador is especially acknowledged for providing financial support for this research.

\section{Conflicts of Interest}

The authors declare no conflicts of interest regarding the publication of this paper.

\section{References}

[1] Martinez-Klimova, E., Rodríguez-Peña, K. and Sánchez, S. (2017) Endophytes as Sources of Antibiotics. Biochemical Pharmacology, 134, 1-17.

https://doi.org/10.1016/j.bcp.2016.10.010

[2] Strobel, G. and Daisy, B. (2003) Bioprospecting for Microbial Endophytes and Their Natural Products. Microbiology and Molecular Biology Reviews, 67, 491-502. https://doi.org/10.1128/MMBR.67.4.491-502.2003

[3] Higginbotham, S.J., Arnold, A.E., Ibañez, A., Spadafora, C., Coley, P.D. and Kursar, T.A. (2013) Bioactivity of Fungal Endophytes as a Function of Endophyte Taxonomy and the Taxonomy and Distribution of Their Host Plants. PLOS ONE, 8, e73192. https://doi.org/10.1371/journal.pone.0073192

[4] Strobel, G. (2006) Harnessing Endophytes for Industrial Microbiology. Current Opinion in Microbiology, 9, 240-244. https://doi.org/10.1016/j.mib.2006.04.001

[5] Aly, A.H., Debbab, A. and Proksch, P. (2011) Fungal Endophytes: Unique Plant Inhabitants with Great Promises. Applied Microbiology and Biotechnology, 90, 1829 1845. https://doi.org/10.1007/s00253-011-3270-y

[6] Gouda, S., Das, G., Sen, S.K., Shin, H.S. and Patra, J.K. (2016) Endophytes: A Treasure House of Bioactive Compounds of Medicinal Importance. Frontiers in Microbiology, 7, 1538. https://doi.org/10.3389/fmicb.2016.01538

[7] Rundell, S.M., Spakowicz, D.J., Narváez-Trujillo, A. and Strobel, S.A. (2015) The Biological Diversity and Production of Volatile Organic Compounds by StemInhabiting Endophytic Fungi of Ecuador. Journal of Fungi, 1, 384-396. https://doi.org/10.3390/jof1030384

[8] dos Santos, I.P., da Silva, L.C.N., da Silva, M.V., de Araújo, J.M., Cavalcanti, M.S. and Lima, V.L.M. (2015) Antibacterial Activity of Endophytic Fungi from Leaves of Indigofera suffruticosa Miller (Fabaceae). Frontiers in Microbiology, 6, 350. https://doi.org/10.3389/fmicb.2015.00350

[9] Brehm, G., Fiedler, K., Häuser, C.L. and Dalitz, H. (2008) Methodological Challenges of a Megadiverse Ecosystem. In: Beck, E., Bendix, J., Kottke, I., Makeschin, F. and Mosandl, R., Eds., Gradients in a Tropical Mountain Ecosystem of Ecuador, Ecological Studies, Springer-Verlag, Berlin, 41-47.

https://doi.org/10.1007/978-3-540-73526-7 5

[10] Skirycz, A., Kierszniowska, S. and Méret, M. (2016) Medicinal Bioprospecting of the Amazon Rainforest: A Modern Eldorado? Trends in Biotechnology, 34, 781-790. https://doi.org/10.1016/j.tibtech.2016.03.006

[11] Bascom-Slack, C.A., Arnold, A.E. and Strobel, S.A. (2012) Student-Directed Discovery of the Plant Microbiome and Its Products. Supplementary Materials. Science, 338, 485-486. https://doi.org/10.1126/science.1215227

[12] Panizel, I., Yarden, O., Ilan, M. and Carmeli, S. (2013) Eight New Peptaibols from Sponge-Associated Trichoderma atroviride. Marine Drugs, 11, 4937-4960. 
https://doi.org/10.3390/md11124937

[13] Friedman, M. (2004) Applications of the Ninhydrin Reaction for Analysis of Amino Acids, Peptides, and Proteins to Agricultural and Biomedical Sciences. Journal of Agricultural and Food Chemistry, 52, 385-406. https://doi.org/10.1021/jf030490p

[14] Arivudainambi, U.S.E., Anand, T.D., Shanmugaiah, V., Karunakaran, C. and Rajendran, A. (2011) Novel Bioactive Metabolites Producing Endophytic Fungus Colletotrichum gloeosporioides against Multidrug-Resistant Staphylococcus aureus. FEMS Immunology and Medical Microbiology, 61, 340-345. https://doi.org/10.1111/j.1574-695X.2011.00780.x

[15] Clinical and Laboratory Standards Institute (2012) Performance Standards for Antimicrobial Susceptibility Testing. Twenty-Second Informational Supplement, Vol. 32, 50-78.

[16] Wiegand, I., Hilpert, K. and Hancock, R.E.W. (2008) Agar and Broth Dilution Methods to Determine the Minimal Inhibitory Concentration (MIC) of Antimicrobial Substances. Nature Protocols, 3, 163-175. https://doi.org/10.1038/nprot.2007.521

[17] Forcina, G.C., Castro, A., Bokesch, H.R., Spakowicz, D.J., Legaspi, M.E., Kucera, K., Villota, S., Narvaez-Trujillo, A., McMahon, J.B., Gustafson, K.R. and Strobel, S.A. (2015) Stelliosphaerols A and B, Sesquiterpene-Polyol Conjugates from an Ecuadorian Fungal Endophyte. Journal of Natural Products, 78, 3005-3010. https://doi.org/10.1021/acs.jnatprod.5b00749

[18] Hutwimmer, S., Wang, H., Strasser, H. and Burgstaller, W. (2010) Formation of Exudate Droplets by Metarhizium anisopliae and the Presence of Destruxins. Mycologia, 102, 1-10. https://doi.org/10.3852/09-079

[19] Gareis, M. and Gottschalk, C. (2014) Stachybotrys spp. and the Guttation Phenomenon. Mycotoxin Research, 30, 151-159. https://doi.org/10.1007/s12550-014-0193-3

[20] Schmidt, K. and Spiteller, D. (2017) Ammonia Released by Streptomyces aburaviensis Induces Droplet Formation in Streptomyces violaceoruber. Journal of Chemical Ecology, 43, 806-816. https://doi.org/10.1007/s10886-017-0870-8

[21] Caraballo-Rodríguez, A.M., Mayor, C.A., Chagas, F.O. and Pupo, M.T. (2017) Amphotericin B as an Inducer of Griseofulvin-Containing Guttate in the Endophytic Fungus Xylaria cubensis FLe9. Chemoecology, 27, 177-185. https://doi.org/10.1007/s00049-017-0243-3

[22] Daker, M., Abdullah, N., Vikineswary, S. and Kuppusamy, U.R. (2009) Production of Antioxidants by Marasmiellus sp. via Solid Substrate Fermentation. American Journal of Food Technology, 4, 36-46. https://doi.org/10.3923/ajft.2009.36.46

[23] Evans, L., Hedger, J., O’Donnell, G., Skelton, B.W., White, A.H., Williamson, R.T. and Gibbons, S. (2010) Structure Elucidation of Some Highly Unusual Tricyclic Cis-Caryophyllane Sesquiterpenes from Marasmiellus troyanus. Tetrahedron Letters, 51, 5493-5496. https://doi.org/10.1016/j.tetlet.2010.08.036

[24] Yang, N., Huang, S., Dai, H., Guo, Z., Lu, X., Wang, Y., Zhao, Y., et al. (2015) Chemical Constituents from Cultures of the Fungus Marasmiellus ramealis (Bull.) Singer. Journal of the Brazilian Chemical Society, 26, 9-13. https://doi.org/10.5935/0103-5053.20140206

[25] Li, Y., Lai, Y., Wang, Y., Liu, N., Zhang, F. and Xu, P. (2016) 1,8-Cineol Protect against Influenza-Virus-Induced Pneumonia in Mice. Inflammation, 39, 1582-1593. https://doi.org/10.1007/s10753-016-0394-3

[26] Shaw, J.J., Berbasova, T., Sasaki, T., Jefferson-George, K., Spakowicz, D.J., Dunican, B.F., Portero, C.E., Narváez-Trujillo, A. and Strobel, S.A. (2015) Identification of a 
Fungal 1,8-Cineole Synthase from Hypoxylon sp. with Specificity Determinants in Common with the Plant Synthases. Journal of Biological Chemistry, 290, 85118526. https://doi.org/10.1074/jbc.M114.636159

[27] de Sena Filho, J.G., Quin, M.B., Spakowicz, D.J., Shaw, J.J., Kucera, K., Dunican, B. Strobel, S.A. and Schmidt-Dannert, C. (2016) Genome of Diaporthe sp. Provides Insights into the Potential Inter-Phylum Transfer of a Fungal Sesquiterpenoid Biosynthetic Pathway. Fungal Biology, 120, 1050-1063. https://doi.org/10.1016/j.funbio.2016.04.001

[28] Strobel, G.A., Torczynski, R. and Bollon, A. (1997) Acremonium sp. A Leucinostatin a Producing Endophyte of European Yew (Taxus baccata). Plant Science, 128, 97-108. https://doi.org/10.1016/S0168-9452(97)00131-3

[29] Macías-Rubalcava, M.L. and Sánchez-Fernández, R.E. (2017) Secondary Metabolites of Endophytic Xylaria Species with Potential Applications in Medicine and Agriculture. Word Journal of Microbiology and Biotechnology, 33, 15. https://doi.org/10.1007/s11274-016-2174-5

[30] Isaka, M., Chinthanom, P., Boonruangprapa, T., Rungjindamai, N. and Pinruan, U. (2010) Eremophilane-Type Sesquiterpenes from the Fungus Xylaria sp. BCC 21097. Journal of Natural Products, 73, 683-687. https://doi.org/10.1021/np100030x

[31] Sawadsitang, S., Mongkolthanaruk, W., Suwannasai, N. and Sodngam, S. (2015) Antimalarial and Cytotoxic Constituents of Xylaria cf. cubensis PK108. Natural Product Research, 29, 2033-2036. https://doi.org/10.1080/14786419.2015.1017724

[32] Patjana, T., Jantaharn, P., Katrun, P., Mongkolthanaruk, W., Suwannasai, N., Senawong, T., Tontapha, S., Amornkitbumrung, V. and McCloskey, S. (2019) Anti-Inflammatory and Cytotoxic Agents from Xylaria sp. SWUF09-62 Fungus. Natural Product Research, 1-10. https://doi.org/10.1080/14786419.2019.1652292

[33] Baraban, E.G., Morin, J.B., Phillips, G.M., Phillips, A.J., Strobel, S.A. and Handelsman, J. (2013) Xyolide, a Bioactive Nonenolide from an Amazonian Endophytic Fungus, Xylaria feejeensis. Tetrahedron Letters, 54, 4058-4060. https://doi.org/10.1016/j.tetlet.2013.05.093

[34] Guo, L., Niu, S., Chen, S. and Liu, L. (2019) Diaporone A, a New Antibacterial Secondary Metabolite from the Plant Endophytic Fungus Diaporthe sp. Journal of Antibiotics, 73, 116-119. https://doi.org/10.1038/s41429-019-0251-3

[35] Li, G., Kusari, S., Kusari, P., Kayser, O. and Spiteller, M. (2015) Endophytic Diaporthe sp. LG23 Produces a Potent Antibacterial Tetracyclic Triterpenoid. Journal of Natural Products, 78, 2128-2132.

https://doi.org/10.1021/acs.jnatprod.5b00170

[36] Chepkirui, C. and Stadler, M. (2017) The Genus Diaporthe: A Rich Source of Diverse and Bioactive Metabolites. Mycological Progress, 16, 477-494.

https://doi.org/10.1007/s11557-017-1288-y

[37] Toghueo, R.M.K. (2020) Bioprospecting Endophytic Fungi from Fusarium Genus as Sources of Bioactive Metabolites. Mycology, 11, 1-21.

https://doi.org/10.1080/21501203.2019.1645053

[38] Stępień, Ł., Lalak-Kańczugowska, J., Witaszak, N. and Urbaniak, M. (2020) Fusarium Secondary Metabolism Biosynthetic Pathways: So Close But So Far Away. In: Mérillon, J.-M. and Ramawat, K.G., Eds., Co-Evolution of Secondary Metabolites, Springer Nature, Berlin, 211-247. https://doi.org/10.1007/978-3-319-96397-6 28

[39] Khan, N., Afroz, F., Begum, M.N., Roy Rony, S., Sharmin, S., Moni, F., Hasand, C.M., Shaha, K. and Sohrab, M.H. (2018) Endophytic Fusarium solani: A Rich Source of Cytotoxic and Antimicrobial Napthaquinone and Aza-Anthraquinone 
Derivatives. Toxicology Reports, 5, 970-976. https://doi.org/10.1016/j.toxrep.2018.08.016

[40] Ajesh, K. and Sreejith, K. (2009) Peptide Antibiotics: An Alternative and Effective Antimicrobial Strategy to Circumvent Fungal Infections. Peptides, 30, 999-1006. https://doi.org/10.1016/j.peptides.2009.01.026

[41] Peravali, J.B., Kotra, S.R., Sobha, K., Nelson, R., Rajesh, K.V. and Pulicherla, K.K. (2013) Antimicrobial Peptides: An Effective Alternative for Antibiotic Therapy. Mintage Journal of Pharmaceutical and Medical Sciences, 2, 1-7.

[42] Mygind, P.H., Fischer, R.L., Schnorr, K.M., Hansen, M.T., Sönksen, C.P., Ludvigsen, S., Raventós, D., Buskov, S., Christensen, B., De Maria, L., Taboureau, O., Yaver, D., Elvig-Jørgensen, S.G., Sørensen, M.V., Christensen, B.E., Kjærulff, S., Frimodt-Moller, N., Lehrer, R.I., Zasloff, M. and Kristensen, H.-H. (2005) Plectasin Is a Peptide Antibiotic with Therapeutic Potential from a Saprophytic Fungus. Nature, 437, 975-980. https://doi.org/10.1038/nature04051

[43] Ibrahim, A., Tanney, J.B., Fei, F., Seifert, K.A., Cutler, G.C., Capretta, A., Miller, J.D. and Sumarah, M.W. (2020) Metabolomic-Guided Discovery of Cyclic Nonribosomal Peptides from Xylaria ellisii sp. nov., a Leaf and Stem Endophyte of Vaccinium angustifolium. Scientific Reports, 10, Article No. 4599. https://doi.org/10.1038/s41598-020-61088-x

[44] Johnson, R.D., Lane, G.A., Koulman, A., Cao, M., Fraser, K., Fleetwood, D.J., Voisey, C.R., Dyer, J.M., Pratt, J., Christensen, M., Simpson, W.R., Bryan, G.T. and Johnson, L.J. (2015) A Novel Family of Cyclic Oligopeptides Derived from Ribosomal Peptide Synthesis of an In Planta-Induced Gene, Giga, in Epichloë Endophytes of Grasses. Fungal Genetics and Biology, 85, 14-24. https://doi.org/10.1016/j.fgb.2015.10.005

[45] Abdalla, M.A. and McGaw, L.J. (2018) Natural Cyclic Peptides as an Attractive Modality for Therapeutics: A Mini Review. Molecules, 23, 2080.

https://doi.org/10.3390/molecules23082080

[46] Balslev, H., Navarrete, H., De la Torre, L. and Macía, M.J. (2008) Introducción. In: De la Torre, L., Navarrete, H., Muriel, M.P., Macía, M.J. and Balslev, H., Eds., Enciclopedia de las Plantas Útiles del Ecuador, Herbario QCA y Herbario AAU, Quito y Aarhus, 1-3.

[47] Malhadas, C., Malheiro, R., Pereira, J.A., Guedes de Pinho, P. and Baptista, P. (2017) Antimicrobial Activity of Endophytic Fungi from Olive Tree Leaves. World Journal of Microbiology and Biotechnology, 33, 1-12. https://doi.org/10.1007/s11274-017-2216-7

[48] Kusari, S. and Spiteller, M. (2012) Metabolomics of Endophytic Fungi Producing Associated Plant Secondary Metabolites: Progress, Challenges and Opportunities. In: Roessner, U., Ed., Metabolomics, InTech, Rijeka, 241-266. https://doi.org/10.5772/31596

[49] Arnold, A.E. and Lutzoni, F. (2007) Diversity and Host Range of Foliar Fungal Endophytes: Are Tropical Leaves Biodiversity Hotspots? Ecology, 88, 541-549. https://doi.org/10.1890/05-1459 